05,11

\title{
Фазовые переходы в жесткой доменной структуре феррит-гранатовой пленки
}

\author{
() Ю.А. Сирюк, А.В. Безус, Е.Д. Бондарь, В.В. Кононенко
}

Донецкий национальный университет,

Донецк, Украина

E-mail: juliasiryuk@gmail.com

Поступила в Редакцию 9 декабря 2018 г.

В окончательной редакции 12 февраля 2019 г.

Принята к публикации 13 февраля 2019 г.

Изучены спонтанные и индуцируемые магнитным полем фазовые переходы в жесткой доменной структуре одноосной феррит-гранатовой пленки. Показано, что температурный и полевой интервалы устойчивости решетки цилиндрических магнитных доменов зависят от структуры доменных границ.

Ключевые слова: феррит-гранатовая пленка, фазовые переходы, доменная граница, магнитные домены, вертикальная блоховская линия.

DOI: 10.21883/FTT.2019.07.47833.338

\section{1. Введение}

Проблема устойчивости доменных структур при изменении температуры или магнитного поля смещения $(H)$ давно привлекает внимание и экспериментаторов, и теоретиков [1-3]. После того, как Бобек предложил использовать цилиндрические магнитные домены (ЦМД) в устройствах вычислительной техники для записи и хранения информации [4], начался этап бурных исследований доменных структур разных материалов - носителей ЦМД. Поскольку ферритгранатовые пленки были выращены для технического применения в запоминающих устройствах, которые работают на ЦМД-структурах, то в первую очередь исследовались динамические характеристики доменной структуры (ДС). Статические характеристики были изучены мало, и при их изучении не ставился вопрос о степени равновесности изучаемой ДС.

В зависимости от условий роста были получены пленки с разной величиной одноосной анизотропии. При определенном соотношении констант одноосной и кубической анизотропии оказалось возможным появление новых видов доменных структур. Для изготовления пленок с заданными характеристиками появилась необходимость исследовать поведение доменной структуры в широком интервале полей и температур, т. е. исследовать статические характеристики доменной структуры.

Для лучшего продвижения ЦМД и подавления жестких доменов были выращены двухслойные пленки. Кроме того, при определенных условиях роста некоторые пленки, которые растились как однослойные, имели разные магнитные характеристики по толщине, т.е. оказались многослойными. Появилась необходимость исследовать влияние взаимодействия слоев на доменную структуру. И, конечно же, необходимо было изучать поведение доменной структуры и уметь прогнозировать его там, где наблюдаются магнитные особенности, а именно в окрестностях температуры спиновой переориентации, точки магнитной компенсации и температуры Кюри.

В последствии выяснилось, что чисто одноосная анизотропия, обеспечивая статическую устойчивость ЦМД оказалась неспособной поддерживать динамическую устойчивость доменных границ при больших скоростях движения доменов, что ограничивало скорость записи информации. ЦМД-устройства утратили свою актуальность. Появились быстродействующие колоссальной емкости электромеханические запоминающие устройства на жестких дисках.

Тем не менее, интерес к исследованию эпитаксиальных пленок феррита-граната остается устойчивым до настоящего времени. Это объясняется тем, что степени проявления различных эффектов в таких пленках гораздо выше, чем у объемных монокристаллов того же свойства. В результате появились работы по изучению индуцируемых магнитным полем фазовых переходов в пленках с положительной константой анизотропии $[5,6]$. В них определено положение границ устойчивости для основных типов доменов: простой полосовой ДС, полосовой ДС с периодическими изгибными поверхностными искажениями профиля доменных границ и гексагональных решеток ЦМД. В [7] изучены фазовые переходы между монопериодическими и синфазными бипериодическими доменными структурами. Установлено, что эти фазовые переходы происходят через двумерные доменные массивы, аморфизованные по расположению приповерхностных искажений профиля доменных границ. В [8] исследовано поведение динамической магнитной восприимчивости квазиодноосных пленок феррита-граната при спонтанных фазовых переходах в окрестности точки Кюри. В [9] экспериментально исследовано влияние монопериодических и бипериодических полей подмагничивания на процессы зарождения доменных структур в квазиодноосных магнитных пленках в окрестности 
точки Кюри. Обнаружено, что в определенных случаях при медленном охлаждении пленок реализуются цепочки фазовых переходов типа „чертова лестница“. В работах [10,11] изучены спин-переориентационные фазовые переходы (СПФП). В [10] построена теория динамической спиновой переориентации в антиферромагнетике под действием фемтосекундного лазерного импульса. Показано, что даже слабый разогрев спиновой подсистемы может существенно усилить эффект переориентации. Обсуждается возможность применения этого эффекта для повышения эффективности возбуждения спиновых колебаний. В [11] экспериментально исследована пленка гольмиевого феррита-граната. Этот материал обладает рядом интересных свойств, таких, как большая магнитострикция, мультиферройность и т. д. Сложная форма петель гистерезиса и резкая перестройка доменной структуры при изменении температуры позволила определить наличие переходов из коллинеарной в неколлинеарную фазу. В пленках с разной величиной одноосной анизотропии изучены особенности доменных границ при спиновой переориентации $[12,13]$.

В [14] изучены свойства эпитаксиальных пленок феррита-граната с (210)-ориентацией. Показано, что в таких пленках проявляется магнитоэлектрический эффект. В [15] выполнен теоретический анализ возможности экспериментальных проявлений нелинейных магнитоэлектрических эффектов в изотропном неупорядоченном диэлектрике под действием неоднородных электрических и магнитных полей $[15,16]$. В рамках феноменологической эластомагнитоэлектростатики изучено взаимодействие электрической, магнитной и упругой подсистем в неупорядоченных микрополярных средах [16]. Показано, что неупорядоченные внутренние и внешние вращения создают не только упругие напряжения, но и дополнительные электрические и магнитные индукции, а неоднородные упругие напряжения и внешние поля индуцируют внутреннее вращение. Нелокальный характер микрополярных сред оказывает также значительное воздействие на элементарные возбуждения и нелинейные динамические процессы. В случае одноосных ферритгранатовых пленок действие внешних магнитных полей в первую очередь сказывается на структуре доменных границ. В [17] изучены особенности перемагничивания феррит-гранатовой пленки во внешних магнитных полях, параллельных и перпендикулярных плоскости пленки. Обнаружено, что между состояниями с различными распределениями магнитного момента при изменении напряженности и направления внешнего магнитного поля происходят фазовые переходы первого и второго рода.

Из перечня приведенных работ видно, что исследователей интересуют фазовые переходы в доменных структурах и поведение доменных границ при изменении температуры и внешних магнитных полей. В наших работах $[12,13]$ исследованы особенности доменных границ при спин-переориентационных фазовых переходах первого и второго рода. В настоящей работе изучены фазовые переходы в жесткой решетке ЦМД одноосной пленки феррита-граната при изменении температуры или внешнего магнитного поля. Выяснена роль доменных границ в фазовых переходах доменной структуры.

Предварительные результаты исследований были доложены на международных конференциях [18-20].

\section{2. Общие сведения о структуре доменных границ и изучении особенностей гексагональных решеток ЦМД одноосных феррит-гранатовых пленок}

Магнитные доменные структуры представляют собой периодически чередующиеся области с антипараллельным направлением намагниченности, разделенные доменными границами (ДГ). Доменные границы являются неоднородными структурами, в которых происходят изменения ориентации спинов от направления спинов в одном домене к направлению спинов в соседнем домене. Структура ДГ зависит от выбранного кристаллографического направления пленки, ее толщины, температуры и действия магнитных полей $[21,22]$. При рассмотрении распределения спинов в доменной границе предполагается, что при переходе через границу нормальная составляющая спинового магнитного момента не испытывает изменений, так как в этом случае полная магнитостатическая энергия минимальна. При этом намагниченность в доменной границе лежит в плоскости стенки, и на поверхности стенки не возникают магнитные заряды. Это означает, что поворот спинов по толщине ДГ можно уподобить винтовому вращению. Такие доменные стенки называются доменными границами Блоха и представляют собой наиболее общий тип доменных границ в ЦМД-материалах, так как они минимизируют энергию размагничивания. Симметрия допускает два возможных направления поворота намагниченности в ДГ - правовинтовое и левовинтовое. В доменной границе Нееля спины распределяются с нарушением правила непрерывности нормальной составляющей. При этом оказывается более выгодным поворот в плоскости, параллельной плоскости пленки [23,24].

В эпитаксиальных пленках с осью легкого намагничивания, перпендикулярной развитой поверхности пленки, доменная граница Блоха наблюдается в широком температурном интервале вплоть до температуры Нееля. И только при приближении к точке компенсации, где растет величина константы кубической анизотропии и характеристическая длина пленки, ДГ Блоха переходит в доменную границу Нееля. Если в пленке формировать решетку ЦМД импульсным магнитным полем, перпендикулярным плоскости пленки, то создается доменная граница ЦМД, имеющая сложную структуру. В границе ЦМД создается большое число поворотов спинов двух направлений (полярностей), как левовинтовых, так и правовинтовых. Линия, разделяющая два участка стенки Блоха с различными полярностями, проходит вертикально через пленку, и такую структуру назвали вертикальной линией Блоха (ВБЛ). Число линий Блоха в ЦМД 
должно быть четным, т. е. в стенке ЦМД могут находиться только пары линий Блоха. Длина окружности ЦМД представляет собой граничное условие, которое заставляет линии Блоха сближаться до интервала $s=\pi d / 2 N$, где $d$ - диаметр ЦМД, $N$ - число оборотов спинов, $s$ - расстояние между ВБЛ. Для ЦМД с диаметром 4-13 $\mu$ m получено максимальное значение $N=90$, что соответствует 180 линиям ВБЛ [24].

При изменении температуры $(T)$ изменяются магнитные характеристики феррита-граната: намагниченность насыщения $\left(4 \pi M_{s}\right)$, характеристическая длина $(l)$, поверхностная плотность энергии доменных границ $\left(\sigma=4 \pi M_{s}^{2} l\right)$. Это сказывается на особенностях доменной структуры: ее виде, структуре доменных границ, фазовых переходах в ДС.

Определение механизма фазовых переходов в доменной структуре актуально как для фундаментальной физики, так и в прикладном плане, например, в микроэлектронике и спинтронике. Процессы, подобные тем, что наблюдаются в феррит-гранатовых пленках, происходят и в других твердых телах: упорядочение и разупорядочение, фазовые переходы и т.д. но, к сожалению, они недоступны для непосредственного наблюдения и изучаются косвенными методами. Преимущества ферритгранатовых пленок в том, что в них возможна визуализация происходящих процессов благодаря эффекту Фарадея. Эпитаксиальные пленки ферритов-гранатов - это прекрасный модельный объект для изучения механизма фазовых переходов в твердых телах.

Так как доменная структура является термодинамической системой, то распределение доменов происходит таким образом, чтобы общая энергия системы была минимальна. Внешнее магнитное поле нарушает магнитное равновесие доменов, под его воздействием область доменов с противоположной полю намагниченностью уменьшается. Если это полосовые домены, то уменьшается их ширина, если цилиндрические магнитные домены - то диаметр. При определенной величине $H<H_{C}$ такие домены исчезают, т.е. коллапсируют. Первыми коллапсируют полосовые домены, затем решетка ЦМД, а потом ЦМД.

Аналитическая теория решетки ЦМД развита в работах [25-27], согласно которым учет поля не изменяет энергию доменных границ и магнитостатическую энергию. В то же время учет поля приводит к необходимости учета энергии взаимодействия намагниченности с магнитным полем. При приближении поля смещения к полю коллапса происходит перестройка доменов, связанная с развитием неустойчивости [26]. При этом должен коллапсировать каждый третий ЦМД и увеличиваться период решетки $a$. В [28] экспериментально наблюдалась перестройка решетки ЦМД вблизи поля коллапса, связанная с появлением динамической неустойчивости. Было обнаружено, что значения поля, при которых происходит перестройка, отделены друг от друга конечными интервалами, уменьшающимися с ростом периода решетки.
В [29] исследовалось влияние поля смещения на плотность и температурную стабильность решетки ЦМД в широком температурном интервале. Было показано, что при формировании решетки ЦМД в поле смещения возникает термодинамически равновесная решетка, а наложение внешнего поля на сформированную решетку приводит ее в неравновесное состояние. В [30] на основе экспериментальных результатов развита термодинамическая теория, позволяющая описать влияние внешних магнитных полей на фазовые переходы в решетке ЦМД. Теоретически были определены границы устойчивого, неустойчивого и метастабильного состояний решетки ЦМД в магнитных полях. Но в работах $[29,30]$ не учитывалась роль доменных границ в фазовых переходах доменной структуры. Доменные границы, благодаря своей структуре, очень чувствительны к изменению температуры или магнитного поля. В работах $[18,31]$ изучены спонтанные фазовые переходы в ДС феррит-гранатовой пленки в температурном интервале от точки компенсации до температуры Нееля. Показано, что при изменении температуры или магнитного поля фазовые переходы в доменной границе вызывают фазовые переходы в решетке ЦМД, а температурный интервал устойчивости решетки ЦМД зависит от структуры доменных границ.

Цель настоящей работы - изучить влияние температуры и магнитного поля смещения на решетку ЦМД, на домены и на доменные границы.

Актуальность этой работы в том, что исследования, проведенные в ней, могут быть использованы при создании устройств записи и хранения информации на спинах доменных границ. В данных устройствах возможна одновременная и/или параллельная запись и хранение информации на доменах и на спинах, что существенно может расширить возможности таких устройств.

\section{3. Спонтанные фазовые переходы в решетке цилиндрических магнитных доменов}

Для исследования выбрана пленка с развитой поверхностью $\langle 111\rangle$, выращенная методом жидкофазной эпитаксии на гадолиний-галлиевой подложке состава $(\mathrm{TmBi})_{3}(\mathrm{FeGa})_{3} \mathrm{O}_{12}\left(T_{N}=437 \mathrm{~K}, T_{C}=120 \mathrm{~K}\right)$, где $T_{N}$ температура Нееля, $T_{C}$ - температура магнитной компенсации. Пленка имеет при комнатной температуре фактор качества $Q>5$. При такой величине фактора качества в доменной границе действием импульсного магнитного поля создаются вертикальные блоховские линии [24]. Доменная структура наблюдается благодаря магнитооптическому эффекту Фарадея.

Пленка имеет сильную одноосную анизотропию, вследствие чего в широком температурном интервале при $T>T_{C}$ наблюдается осевая фаза, т.е. создаются ЦМД. Гексагональная решетка ЦМД формируется импульсным магнитным полем, перпендикулярным плоскости пленки, в отсутствии поля смещения. Затем импульсное поле выключается. Такая решетка является 


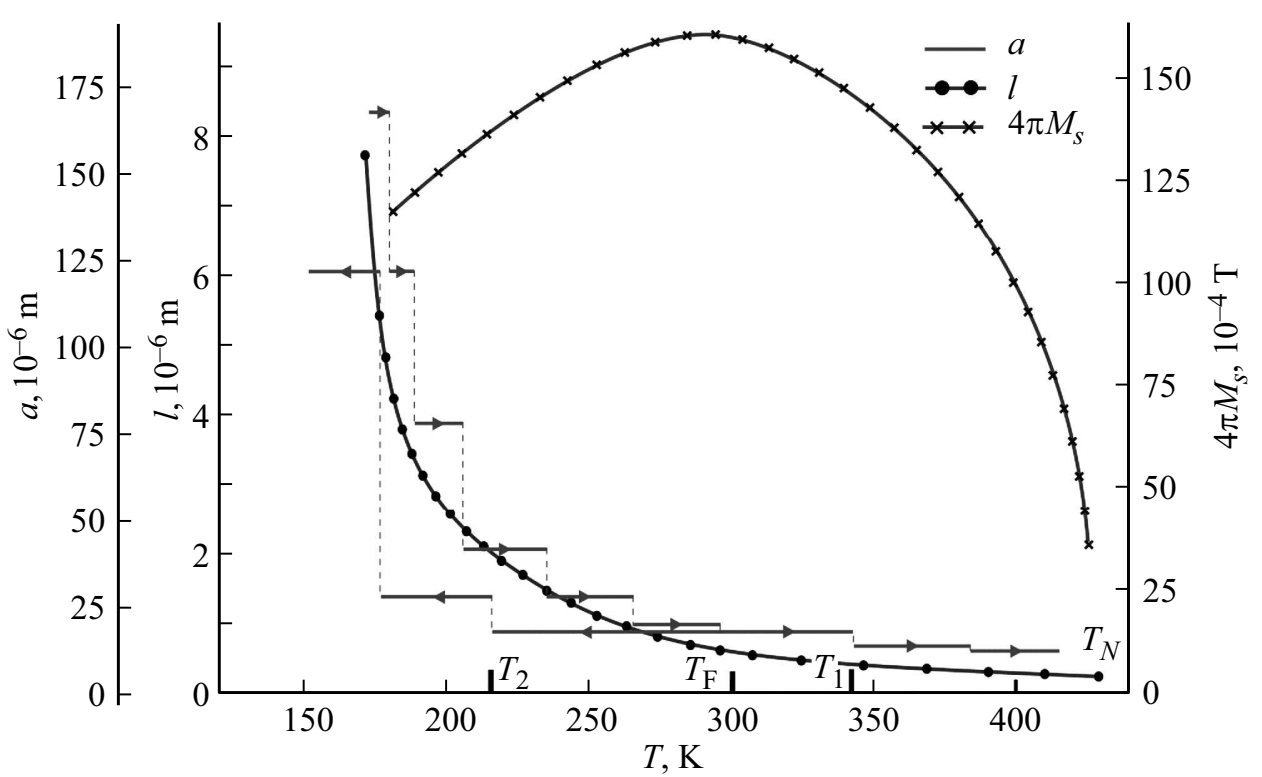

Рис. 1. Температурные зависимости намагниченности насыщения $4 \pi M_{S}$, характеристической длины $l$ и параметра решетки ЦМД $a$ пленки.

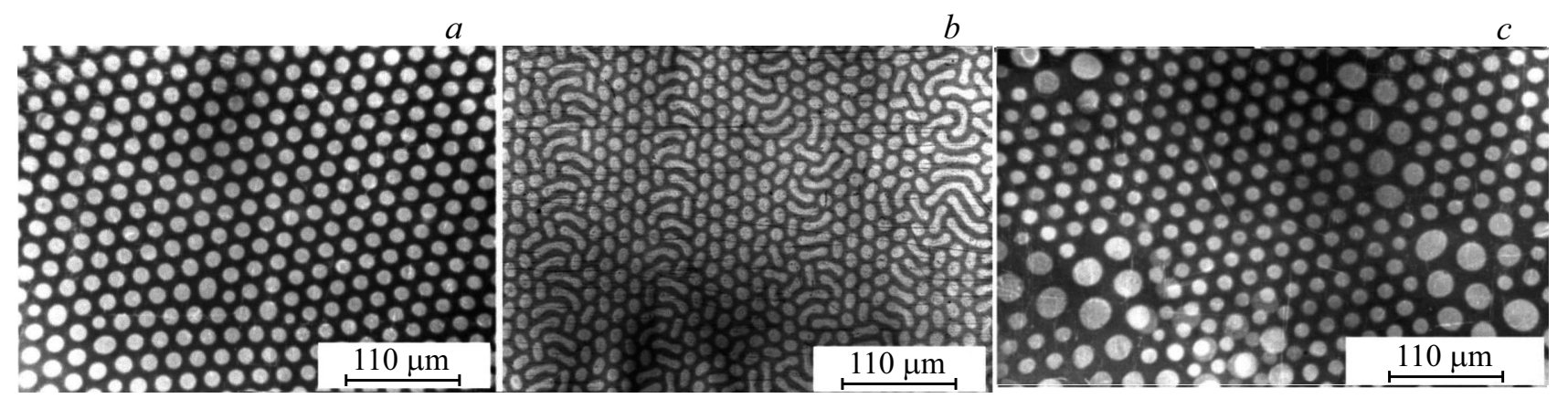

Рис. 2. Виды доменных структур пленки: $a-$ решетка ЦДМ при $300 \mathrm{~K} ; b-\Phi П$ в решетке при $T_{1} ; c-$ ФП в решетке при $T_{2}$.

равновесной при температуре формирования [32]. При эксперименте в качестве критерия равновесности применяются два фактора: 1 - решетка сохраняется неограниченное время при температуре формирования; 2 - ее можно вновь создать с теми же параметрами (диаметром ЦМД и периодом решетки $a$ ). На рис. 1 приведены температурные зависимости магнитных характеристик пленки.

При $300 \mathrm{~K}$ создается решетка ЦМД (рис. 2, a). Температурные зависимости периода решетки $a(T)$ и диаметра ЦМД $d(T)$ подобны зависимости $l(T)$ (рис. 1$)$.

Под действием импульсного магнитного поля создаются жесткие доменные границы с большим количеством ВБЛ. В жестких доменах имеются две силы (сила отталкивания ВБЛ и магнитостатическая сила), которые уравновешиваются сжимающими силами поверхностного натяжения стенки Блоха.

В решетке ЦМД, как в любой термодинамической системе, происходит перераспределение сил таким образом, чтобы был минимум энергии. Поэтому в доменных границах ЦМД, составляющих решетку, импульсным магнитным полем формируется хотя и большое число ВБЛ, но, тем не менее, их количество меньше, чем в одиночных доменах. Учитывая силы, действующие на доменную границу и температурные зависимости характеристик пленки (рис. 1), при этой температуре создается максимальное число ВБЛ в ДГ (точка $A$ на рис. 3). Для равновесной решетки ЦМД температурная зависимость числа ВБЛ изображена кривой 1 на рис. 3 .

Если же решетку ЦМД сформировать при $300 \mathrm{~K}$, а затем изменять $T$ пленки, то решетка сохраняется (хотя является уже неравновесной) в температурном интервале $T_{1}-T_{2}$ (рис. 1,3), на обоих концах которого происходят фазовые переходы. При $T_{1}$ в решетке ЦМД происходит фазовый переход первого рода в двухфазную структуру с сохранением числа доменов (рис. 2, $b$ ). Этот фазовый переход вызван фазовым переходом в доменной границе. При этом число ВБЛ в доменной границе уменьшилось путем аннигиляции (точка $C_{1}$ на рис. 3). При $T_{2}$ в решетке происходит фазовый переход первого рода в новую решетку ЦМД с уменьшением числа доменов (рис. 2,c) [31]. При этом в доменной границе происходит фазовый переход с уменьшением 


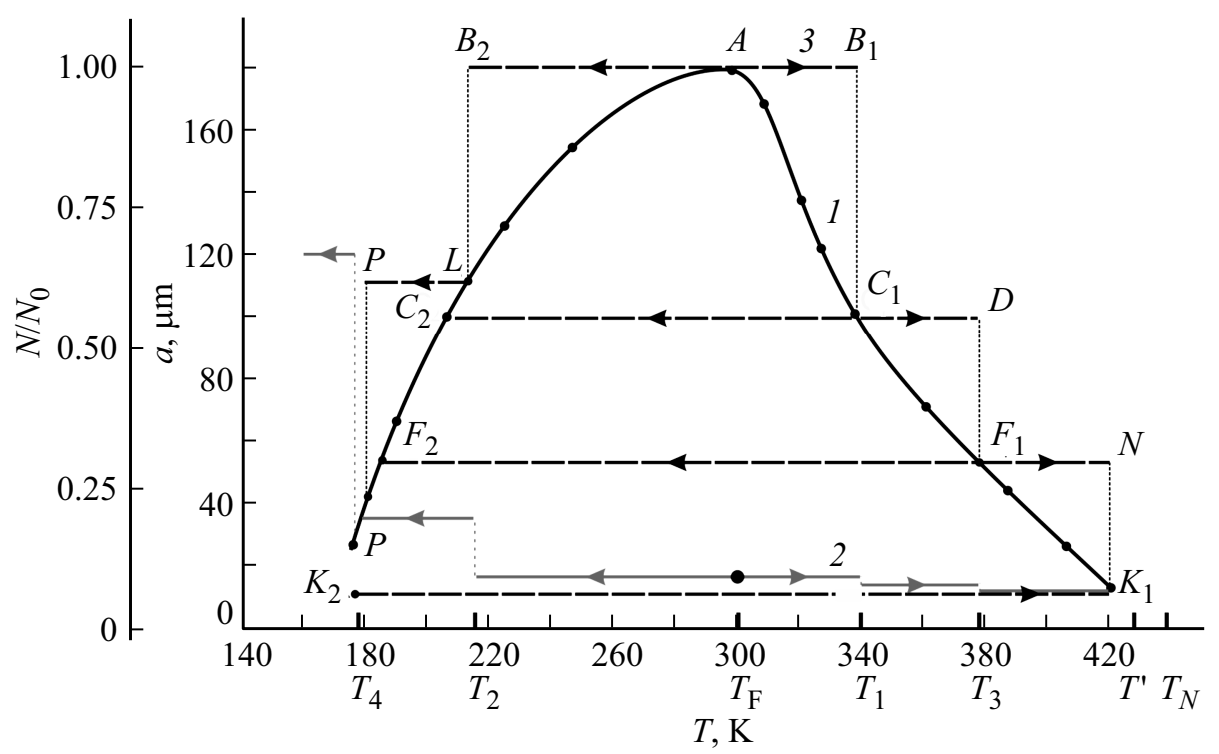

Рис. 3. Температурные зависимости параметров решеток ЦМД: $1-N / N_{0}$ ВБЛ в ДГ равновесной решетки; $2-$ период неравновесной решетки; $3-N / N_{0}$ ВБЛ в ДГ неравновесной решетки.

числа ВБЛ путем раскручивания (точка $C_{2}$ на рис. 3). Фазовые переходы при температурах $T_{1}$ и $T_{2}$ являются фазовыми переходами первого рода как в решетке ЦМД, так и в доменной границе. В исследуемом температурном интервале таких фазовых переходов в доменной границе и в решетке наблюдается несколько (рис. 1) [32]. Наблюдаемые экспериментальные данные приведены в таблице.

Из рис. 3 видно, что температурные интервалы устойчивости $\Delta T$ неравновесных решеток ЦМД зависят от числа ВБЛ в доменной границе. Так, при максимальном числе ВБЛ в доменной границе (точка $A$ на рис. 3) температурный интервал устойчивости равен $B_{1}-B_{2}$. При меньшем числе ВБЛ (точка $C_{1}$ ) температурный интервал устойчивости увеличивается $\left(C_{2}-D\right)$. И при простой блоховской стенке, которая создается при $T=0.98 T_{N}[31]$, температурный интервал устойчивости максимален $\left(K_{1}-K_{2}\right)$.

\section{4. Индуцируемые магнитным полем фазовые переходы в доменной структуре}

В работе исследуется при $T=300 \mathrm{~K}$ два вида решеток. Первая - РЦД 1 , формируется импульсным магнитным полем, перпендикулярным плоскости пленки, при отсутствии поля смещения; вторая - РЦД2, формируется импульсным полем в присутствии поля смещения. Затем импульсное поле выключается. Обе решетки являются равновесными, но при наложении поля смещения РЦД 1 оказывается неравновесной, а РЦД 2 , формируемая при разных полях смещения, является равновесной [29].

Под действием импульсного магнитного поля создаются жесткие доменные границы с большим количеством ВБЛ. Как было отмечено выше, в жестких доменах имеются две силы (сила отталкивания ВБЛ и магнитостатическая сила), которые уравновешиваются сжимающими силами поверхностного натяжения стенки Блоха. Стенки Блоха и поле смещения дают статически устойчивый домен. Из [24] следует, что жесткие ЦМД квантуются, т. е. могут иметь дискретные состояния, различающиеся числом ВБЛ. Следовательно, квантуются и доменные границы. Обнаружено, что для типичных гранатовых пленок разница в размерах доменов с различными состояниями порядка $0.1 \mu \mathrm{m}$ или меньше. Поэтому из-за таких малых размеров не было обнаружено убедительных экспериментальных результатов квантования статических характеристик жестких доменов.

При $T=300 \mathrm{~K}$ и $H=0$ создана решетка ЦМД (рис. 4,a). При формировании РЦД 1 импульсное поле создает такое количество ЦМД, при котором общая энергия решетки оказывается минимальной. Плотность

Механизм фазовых переходов в ДГ

\begin{tabular}{c|c|c}
\hline $\begin{array}{c}\text { Температурный } \\
\text { интервал }\end{array}$ & $\begin{array}{c}\text { Изменение магнитных характеристик } \\
\text { пленки с температурой }\end{array}$ & Механизм ФП в ДГ \\
\hline$T_{F}-T_{1}$ & $T \uparrow, M_{S} \downarrow, l \downarrow, \sigma \downarrow \Rightarrow d \downarrow, a \downarrow, N \downarrow$ & ФП І рода в ДГ путем аннигиляции \\
$T_{F}-T_{2}$ & $T \downarrow, M_{S} \downarrow, l \uparrow, \sigma \uparrow \Rightarrow d \uparrow, a \uparrow, N \downarrow$ & ФП І рода в ДГ путем раскручивания
\end{tabular}




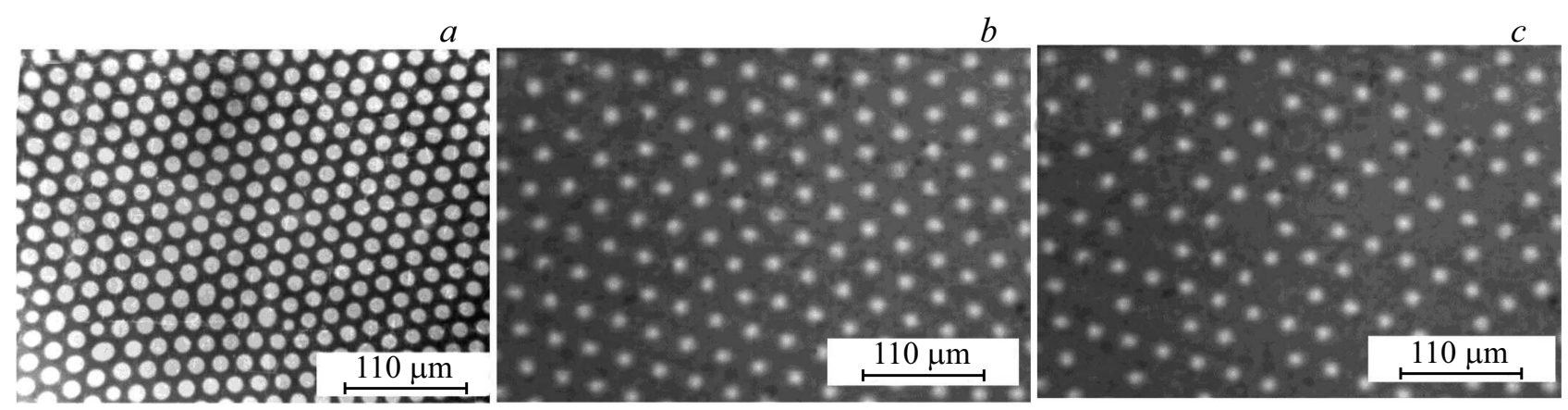

Рис. 4. Виды ДС пленки при различных магнитных полях: $a-$ РЦД $(H=0), b-H>0, c-H=H_{C}$ РЦД.

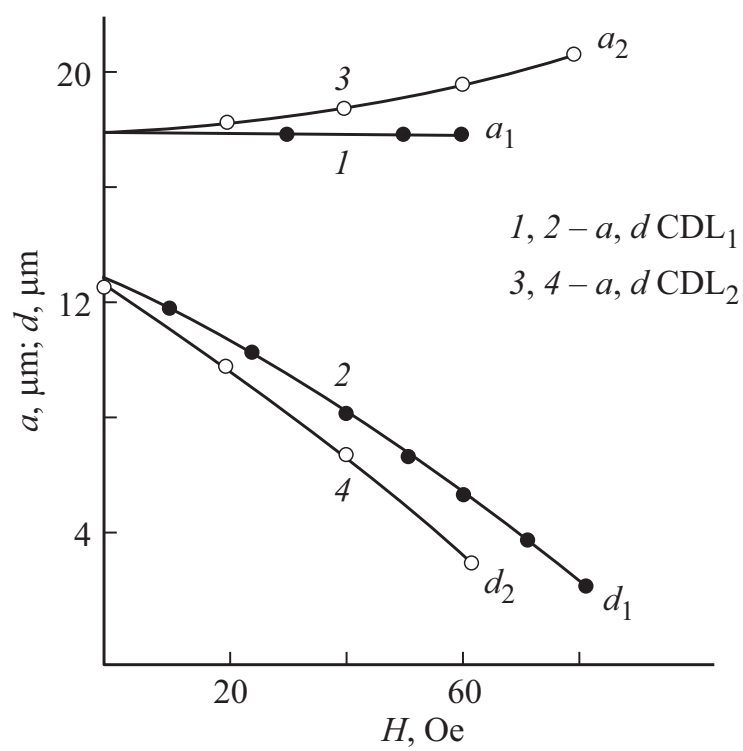

Рис. 5. Полевые зависимости периода РЦД $(a)$ и диаметра ЦМД $(d): 1,2$ - неравновесной РЦД $; 3,4$ - равновесной РЦД2.

упаковки такой решетки $y=d / a=0.74$ [31,32]. При наложении поля смещения к магнитостатической энергии решетки добавляется зеемановская энергия, плотность которой различна внутри и вне домена, что приводит к изменению диаметра ЦМД. Но эти энергии не могут изменить количества ЦМД, поэтому период РЦД 1 остается постоянным при наложении поля смещения. При температуре $300 \mathrm{~K}$ создается максимальное $\left(N_{0}\right)$ число ВБЛ в доменной границе (в относительных единицах $N / N_{0}=1$ на рис. 3). С увеличением поля смещения $H$ диаметр ЦМД уменьшается, а период РЦД остается постоянным (рис. $4, b$, рис. 5 , кривые 1,2 ). При $H=H_{C 1}$ наблюдается коллапс РЦД 1 , при котором исчезает каждый центральный домен гексагональной упаковки (рис. 4,c), т. е. происходит фазовый переход первого рода в решетке ЦМД. Нарушается магнитное равновесие системы. При этом в доменной границе ЦМД резко уменьшается количество ВБЛ (рис. 6, отрезок $C_{1} B$ ). При кратковременном действии импульсного магнитного поля восста- навливается полотно гексагональной решетки ЦМД с меньшей плотностью упаковки $y$, с меньшим диаметром домена и большим периодом $a$. Параметры этой решетки соответствуют параметрам РЦД2 при значении поля $H=H_{C 1}$ (рис. 5, кривые 3,4 ).

Экспериментально наблюдается процесс последовательного коллапсирования решеток при увеличении магнитного поля смещения до $H=H_{C 3}=H_{C}$ ЦМД (рис. 6,5). Из рис. 6 видно, что значения полей, при которых происходит перестройка, отделены друг от друга конечными интервалами, уменьшающимися с ростом периода решетки $\left(D C_{3}<B C_{2}<A C_{1}\right)$. Есть предельная, максимальная величина периода, при которой решетка может существовать в поле $H \leq H_{C}$ РЦД2, т. е.

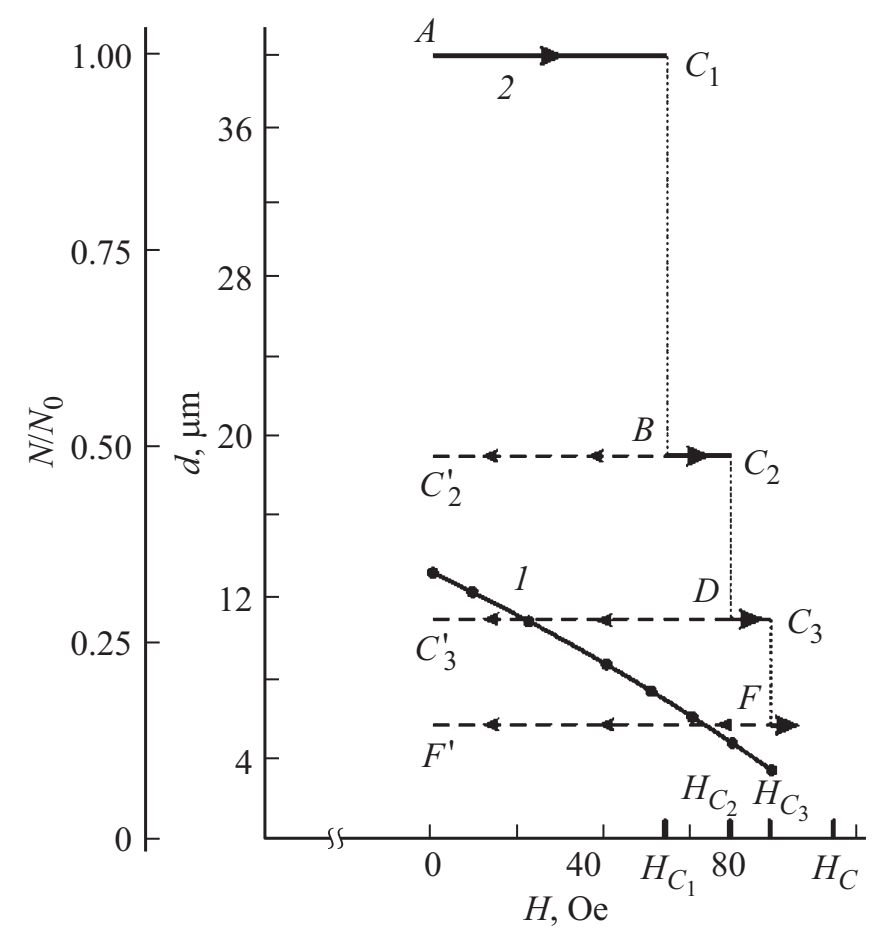

Рис. 6. Полевые зависимости параметров пленки при $T=$ const: 1 - диаметр ЦМД равновесной РЦД $2 ; 2$ - относительное число ВБЛ $\left(N / N_{0}\right)$ в доменной границе неравновесной РЦД 


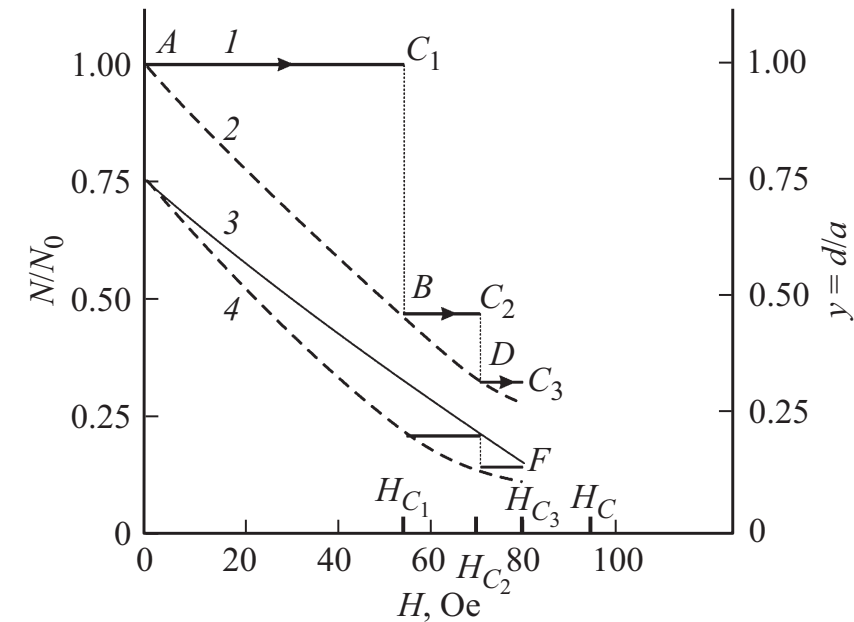

Pис. 7. Полевые зависимости относительного числа ВБЛ в доменной границе и плотности упаковки решетки ЦМД: 1 $\left(N / N_{0}\right)$ РЦД $; 2-\left(N / N_{0}\right)$ РЦД $2 ; 3-(y)$ РЦД $; 4-(y)$ РЦД.

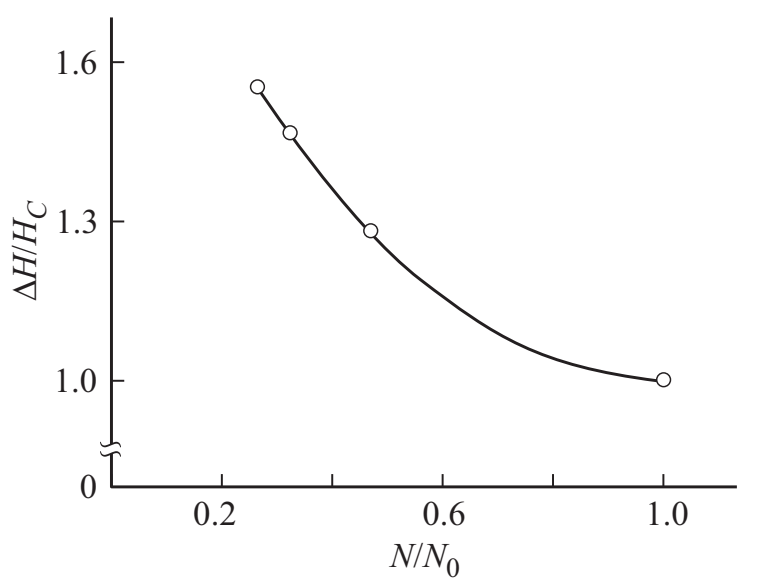

Рис. 8. Зависимость полевого интервала устойчивости РЦД от количества ВБЛ в доменной границе пленки.

$a \leq a_{\text {СРцд }}$. Таким образом, как процесс формирования РЦД 2 в поле $H \leq H_{C 3}$, так и наблюдение последовательного коллапсирования решеток, полученных из исходной РЦД 1 , приводят к одинаковому выводу: есть предельный, максимальный период, при котором еще может существовать решетка ЦМД, т. е. при котором еще силы дипольного взаимодействия удерживают систему в динамическом равновесии. Это хорошо иллюстрирует рис. 7. РЦД 1 , сформированная при $H=0$, неравновесна, но динамически устойчива в интервале поля $o \leq H<H_{C 1}$. В доменной границе ЦМД содержится максимальное число ВБЛ $\left(N / N_{0}=1\right)$. При $H=H_{C 1}$ динамическая устойчивость нарушается. В РЦД 1 происходит фазовый переход первого рода. При этом уменьшается диаметр ЦМД. Длина окружности ЦМД представляет собой граничное условие, которое заставляет линии Блоха сближаться до интервала $S=\pi d / 2 N$ [24]. В итоге при
$H=H_{C 1}$ происходит резкое уменьшение количества ВБЛ в доменной границе путем аннигиляции, т. е. квантуется как сам домен, так и его доменная граница, что и было теоретически предсказано. В доменной границе происходит фазовый переход первого рода. На рис. 7 этот переход отмечен отрезком $C_{1} B$. Точка $B$ лежит на кривой 2. Кривая 2 показывает полевую зависимость числа ВБЛ решетки РЦД2, которая является равновесной. Таких переходов при увеличении поля наблюдается несколько. При всех фазовых переходах в решетках типа РЦД 1 , ее доменах и доменных границах предельное значение периода решетки, диаметра домена $d$ и числа ВБЛ в доменной границе определяются соответствующими величинами равновесной решетки РЦД2. Кривые 3 и 4 на рис. 7 показывают полевые зависимости плотности упаковки неравновесной РЦД 1 и равновесной РЦД2.

Экспериментально было обнаружено, что при изменении поля смещения исходная решетка РЦД 1 может существовать в интервале поля $0 \leq H<H_{C 1}$ (рис. 6, отрезок $\left.A C_{1}\right)$, полученная при $H_{C 1}$ решетка сохраняется в интервале $0<H<H_{C 2}$ (рис. 6, отрезок $C_{2} C_{2}^{\prime}$ ) и, наконец, решетка, полученная при $H=H_{C 2}$, может сохраняться в интервале поля $0<H<H_{C 3}$ (рис. 6, отрезок $C_{3} C_{3}^{\prime}$ ). Таким образом, полевой интервал динамической устойчивости решетки увеличивается с уменьшением числа ВБЛ в доменных границах ЦМД. При $H<H_{C}$ домен имеет простую блоховскую стенку. Решетка, созданная из таких доменов, сохраняется в максимальном полевом интервале (рис. 6, отрезок $F F^{\prime}$, рис. 8 ).

\section{5. Заключение}

Экспериментально изучено влияние температуры и магнитного поля смещения на решетку ЦМД и доменные границы. Обнаружено, что структура доменных границ ЦМД очень чувствительна как к температурному изменению параметров пленки, так и к действию магнитных полей.

При изменении температуры в доменной границе происходят спонтанные фазовые переходы первого рода, которые вызывают фазовые переходы в решетке ЦМД. Механизм фазовых переходов в доменной границе при нагревании и охлаждении пленки имеет существенные отличия. Число ВБЛ в доменной границе уменьшается при нагревании путем аннигиляции, а при охлаждении - путем раскручивания. Температурный интервал устойчивости решетки ЦМД зависит от структуры доменной границы. С уменьшением числа ВБЛ в доменной границе температурный интервал устойчивости решетки ЦМД увеличивается. Решетка ЦМД с простой блоховской стенкой наиболее устойчива и сохраняется в широком температурном интервале.

Изучено влияние магнитного поля при постоянной температуре на два вида решеток: неравновесную РЦД и равновесную РЦД2. Обнаружено, что при увеличении 
магнитного поля наблюдается процесс последовательных фазовых переходов в РЦД 1 , в домене и в доменной границе. При фазовом переходе в решетке исчезает каждый центральный домен в гексагональной упаковке, диаметр оставшихся доменов уменьшается, а период решетки увеличивается. Фазовый переход в границе ЦМД происходит путем аннигиляции ВБЛ. Параметры неравновесной РЦД 1 приобретают значения, равные параметрам равновесной РЦД2 при данной величине поля смещения.

Значения полей, при которых происходят переходы, отделены друг от друга конечными интервалами, уменьшающимися с ростом периода решетки.

Полевой интервал динамической устойчивости решетки увеличивается с уменьшением количества ВБЛ в доменных границах ЦМД. При поле, близком к полю коллапса ЦМД, домен имеет простую блоховскую стенку. Решетка, созданная из таких доменов, сохраняется в максимальном полевом интервале.

\section{Конфликт интересов}

Авторы заявляют, что у них нет конфликта интересов.

\section{Список литературы}

[1] А.К. Звездин, В.А. Котов. Магнитооптика тонких пленок. Наука, М. (1988). 192 с.

[2] В.В. Рандошкин, А.Я. Червоненкис. Прикладная магнитооптика. Энергоиздат, М. (1990). 320 с.

[3] А. Эшенфельдер. Физика и техника цилиндрических магнитных доменов. Мир, М. (1983). 496 с.

[4] A.H. Bobek. Bell. System. Tech. J. 46, 10, 1901 (1967).

[5] Ф.В. Лисовский, Е.Г. Мансветова, Ч.М. Пак. ЖЭТФ 111, 1, 293 (1997).

[6] Г.В. Арзамасцева, Ф.В. Лисовский, Е.Г. Мансветова, М.П. Темирязева. ЖЭТФ 114, 6, (12), 2089 (1998).

[7] Г.В. Арзамасцева, М.Г. Евтихов, Ф.В. Лисовский, Е.Г. Мансветова, М.П. Темирязева. ЖЭТФ 134, 2, (8), 282 (2008).

[8] И.Е. Дикштейн, Ф.В. Лисовский, Е.Г. Мансветова. ЖЭТФ 125, 6, 1317 (2004).

[9] Г.В. Арзамасцева, М.Г. Евтихов, Ф.В. Лисовский, Е.Г. Мансветова. ЖЭТФ 140, 3, (9), 516 (2011).

[10] Е.Г. Галкина, И.Ю. Михайлов, Б.А. Иванов. Письма в ЖЭТФ 93, 12, 792 (2011).

[11] А.М. Калашникова, В.В. Павлов, А.V. Kimel, А. Kirilyuk, Th. Rasing, Р.В. Писарев. ФНТ 38, 9, 1088 (2012).

[12] Я.И. Грановский, А.А. Леонов, Ю.А. Мамалуй, Ю.А. Сирюк, Изв. РАН. Сер. физ. 70, 7, 956 (2006).

[13] Ю.А. Мамалуй, Ю.А. Сирюк, А.В. Безус. ФНТ 37, 2, 150 (2011).

[14] Г.В. Арзамасцева, А.М. Балбашов, Ф.В. Лисовский, Е.Г. Мансветова, А.Г. Темирязев, М.П. Темирязева. ЖЭТФ 147, 4, 793 (2015).

[15] А.Ф. Кабыченков, Ф.В. Лисовский. ЖЭТФ 149, 1,150 (2016).

[16] А.Ф. Кабыченков, Ф.В. Лисовский. ЖЭТФ 150, 2, (8), 293 (2016).
[17] Г.В. Арзамасцева, Ф.В. Лисовский, Е.Г. Мансветова. ФТТ 58, 1, 92 (2016).

[18] Ю.А. Сирюк, А.В. Безус, Е.Д. Бондарь, В.В. Смирнов. Сб. трудов XX Междунар. междисциплинарного симпозиума „ОМА-20“. Ростов-на-Дону, Россия (2017). 209 с.

[19] Ю.А. Сирюк, А.В. Безус, Е.Д. Бондарь, В.В. Смирнов. Сб. трудов Междунар. конф. „Новое в магнитных материалах микроэлектроники (НМММ-XXIII)“. Москва (2018). $222 \mathrm{c}$.

[20] Ю.А. Сирюк, А.В. Безус, Е.Д. Бондарь, В.В. Смирнов. Сб. трудов XXI Междунар. междисциплинарного симпозиума „ОМА-21“. Ростов-на-Дону, Россия (2018). 133 с.

[21] Г.С. Кандаурова. Изв. УрГУ 5, 31 (1977).

[22] В.Г. Барьяхтар, Б.А. Иванов. В мире магнитных доменов. Наук. думка, Киев (1986). 159 с.

[23] Г.С. Кандаурова, Л.Г. Оноприенко. Доменная структура магнетиков. Основные вопросы. УрГУ, Свердловск (1986). $136 \mathrm{c}$.

[24] А. Малоземов, Дж. Слонзуски. Доменные стенки в материалах с цилиндрическими магнитными доменами. Мир, M. (1982). 384 c.

[25] В.Г. Барьяхтар, В.В. Ганн, Ю.И. Горобец. ЖТФ 45, 386 (1975).

[26] В.Г. Барьяхтар, В.В. Ганн, Ю.И. Горобец. ФТТ 18, 1990 (1976).

[27] В.Г. Барьяхтар, Ю.И. Горобец. Цилиндрические магнитные домены и их решетки. Наук. думка, Киев (1988). 168 с.

[28] В.Г. Барьяхтар, Ю.И. Горобец, О.В. Ильчишин, Н.В. Петров. ФТТ 24, 1829 (1977).

[29] Ю.А. Мамалуй, Ю.А. Сирюк. Влияние магнитного поля на фазовые переходы в гексагональных решетках ЦМД. Препринт ДонФТИ АН УССР, Донецк (1986). 38 с.

[30] В.А. Заблоцкий, Ю.А. Мамалуй, Ю.А. Сирюк. Фазовые превращения в решетках цилиндрических магнитных доменов. Препринт ДонФТИ АН УССР, Донецк (1989). 33 с.

[31] Ю.А. Сирюк, А.В. Безус. ФТТ 55, 547 (2013).

[32] Ю.А. Мамалуй, Ю.А. Сирюк, А.В. Безус. ФТТ 45, 1645 (2003).

Редактор Т.Н. Василевская 